\title{
Transcutaneous aortic valve implantation using the axillary/ subclavian access: Feasibility and early clinical outcomes
}

\author{
Thomas Modine, MD, PhD, ${ }^{\mathrm{a}}$ Jean François Obadia, MD, PhD, ${ }^{\mathrm{b}}$ Emmanuel Choukroun, MD, PhD, ${ }^{\mathrm{c}}$ \\ Gilles Rioufoul, MD, PhD, ${ }^{\mathrm{b}}$ Arnaud Sudre, MD, Jean Claude Laborde, MD, PhD, ${ }^{\mathrm{d}}$ and \\ Pascal Leprince, MD, $\mathrm{PhD}^{\mathrm{e}}$
}

\begin{abstract}
Objective: Retrograde transfemoral artery catheterization is the most common way of implanting a percutaneous aortic valve. But in some cases, this access cannot be used and the subclavian artery access may represent an alternative to the femoral route, even offering certain advantages. This article describes prosthetic aortic valve implantation using the subclavian arterial approach and reports the findings.
\end{abstract}

\begin{abstract}
Methods: The valve prosthesis is a self-expandable, nitinol-based device (CoreValve; Medtronic Inc. Minneapolis, Minn). The axillary or subclavian artery was exposed with a small incision. Rapid ventricular pacing was used to reduce cardiac output while a routine aortic balloon valvuloplasty was performed. Then, an $18 \mathrm{~F}$ sheath was inserted into the axillary artery down into the ascending aorta. By using this method, a prosthesis was implanted in 17 patients (aged $71 \pm 11$ years) whose surgical risk was deemed excessive because of severe comorbidity and in whom transfemoral catheterization was considered unfeasible or at risk of severe complications.
\end{abstract}

Results: Subclavian arterial injury did not occur in any patient. The postprocedural aortic valve area increased from $0.6 \pm 0.3 \mathrm{~cm}^{2}$ to $1.44 \pm 0.35 \mathrm{~cm}^{2}$. A transient ischemic attack occurred in 1 patient. Two patients experienced transitory brachial plexus deficit. There were no intraprocedural deaths. Two deaths occurred in the 30-day follow-up period.

Conclusions: This initial experience suggests that subclavian transarterial aortic valve implantation, in selected high-risk patients, is feasible and safe with satisfactory short-term outcomes. (J Thorac Cardiovasc Surg 2011;141:487-91)

Supplemental material is available online.

Aortic valve stenosis is the most frequent adult heart valvular disease in the western world. ${ }^{1}$ Patients are often high-risk candidates for open surgery using a heart-lung machine. ${ }^{2}$ Although surgical valve replacement remains the "gold standard" treatment, many patients with severe aortic stenosis do not undergo surgery for the following reasons: patient refusal, excessive surgical risk, advanced age, or selfpreference. Prognosis with medical management is poor, and the percutaneous approach as an alternative to surgery has been limited to palliative balloon valvuloplasty. ${ }^{3-5}$

Transcutaneous aortic valve implantation (TAVI) has been under active investigation in many medical centers. ${ }^{6-12}$

\footnotetext{
From the CHRU de Lille, ${ }^{\mathrm{a}}$ Paris, France; CHRU de Lyon, ${ }^{\mathrm{b}}$ Paris, France; CHRU de Bordeaux, ${ }^{\mathrm{c}}$ Paris, France; Department of Interventional Cardiology, ${ }^{\mathrm{d}}$ Clinique Pasteur, Toulouse, France; and Lapitié Salpétrière, ${ }^{\mathrm{e}}$ Paris, France.

Disclosures: Dr Laborde is a consultant to CoreValve Inc, Irvine, California; Dr Leprince is a CoreValve proctor.

Received for publication Oct 12, 2009; revisions received Jan 4, 2010; accepted for publication Jan 12, 2010; available ahead of print May 3, 2010.

Address for reprints: Thomas Modine, MD, PhD, Hôpital Cardiologique, Bd J Leclerc 59037 Lille, France (E-mail: t1modine@yahoo.fr).

$0022-5223 / \$ 36.00$

Copyright (c) 2011 by The American Association for Thoracic Surgery

doi:10.1016/j.jtcvs.2010.01.044
}

However, the technical complexity and associated risks of the antegrade approach limited its development. ${ }^{13,14}$ The retrograde femoral arterial approach is an adaptation of the original aortic valvuloplasty technique and is rapidly spreading worldwide with encouraging results. ${ }^{15}$ Patient selection requires a complete study of the different arterial access points, such as the aorta, aortoiliac, and femoral arteries. However, peripheral artery disease may render iliofemoral access difficult or even impossible in some cases. Retrograde femoral access difficulties, in elderly patients, relate to frequently diseased and tortuous femoral and iliac arteries. These obstacles greatly increase the risk of procedure failure or vascular injury with potentially lethal complications. This high vascular risk has led to the development of transapical or subclavian access techniques that have been recently described in the medical literature. ${ }^{16-18}$ Both techniques offer the advantage of avoiding access site problems and facilitating valve delivery. However, the transapical approach, requiring thoracotomy, is more invasive, making it a high-risk procedure in patients with severe respiratory dysfunction. Moreover, several complications resulting from the introduction of a percutaneous valve holder through the apex of the left ventricle have been reported. ${ }^{16}$

In centers where the medico-surgical approach of this new technique was effective, using the axillary or subclavian artery as a second choice after the femoral artery for 


\section{Abbreviation and Acronym}

TAVI $=$ transcutaneous aortic valve implantation

introducing the device became obvious. In this prospective study, we describe the implantation technique, procedural success, and clinical outcome up to 30 days after TAVI using transaxillary or subclavian access in 17 consecutive patients who were purposely recruited. Procedures were performed in 4 different French centers between January and September of 2009.

\section{MATERIALS AND METHODS Patients}

A prospective, single-arm study was performed, including patients from 4 French centers (CHRU de Lille, $\mathrm{n}=7$; Lapitié Salpétrière, $\mathrm{n}=5$; CHRU de Lyon, $\mathrm{n}=4$; and CHRU de Bordeaux, $\mathrm{n}=1$ ). Patients with severe symptomatic aortic stenosis were referred for a percutaneous procedure because of multiple comorbidities and excessive surgical risk. The cases were selected following the guidelines of the "French Sanitary High Authority." Our objective was to evaluate the feasibility, safety, and clinical outcomes of TAVI via subclavian or axillary artery access of the $18 \mathrm{~F}$ CoreValve Revalving System (Medtronic Inc., Minneapolis, Minn). A heart team of senior interventional cardiologists, cardiac surgeons, and anesthetists formally reviewed patients with a consensus that patients did not have a reasonable surgical option. Patient preference alone for a percutaneous procedure was not considered as an acceptable reason for inclusion. Informed consent was obtained. The operating team always consisted of a cardiac surgeon, an interventional cardiologist, and, in some institutions, an interventional radiologist. All patients underwent transthoracic echocardiography and iliofemoral and coronary angiography. Angiographic computed tomography scan and echo Doppler were used to assess the diameter and patency of the right and left subclavian and axillary arteries when iliofemoral arterial access was considered at high risk of vascular complications. Short segments of calcified or focal stenosis were not considered exclusion criterion.

\section{Prosthetic Valve System}

The CoreValve Revalving System consists of porcine pericardium cut into a trileaflet pattern mounted on a nitinol frame. The diameter of the aortic annulus was measured using the transthoracic echocardiography parasternal long-axis view immediately below the insertion point of the valve leaflets. Moreover, because the aortic annulus is not circular, computed tomography scans were used to measure the shortest and longest diameters. Annulus diameters of 20 to $23 \mathrm{~mm}$ and 23 to $27 \mathrm{~mm}$ were considered appropriate for 26-mm and 29-mm diameter prostheses, respectively. Both valves require an $18 \mathrm{~F}$ introducer sheath. An axillary arterial diameter of $6 \mathrm{~mm}$ was considered adequate for implantation.

Patients were premedicated with a loading dose of clopidogrel and aspirin, and intravenously injected with cefazolin $1 \mathrm{~g}$ immediately before the procedure. The procedure was performed in a catheterization laboratory with operating room-like sterility precautions. A femoral access was used, and a $5 \mathrm{~F}$ pigtail catheter was inserted for control angiograms during valve implantation. Vein access for the temporary pacemaker lead was used for rapid pacing during valvuloplasty. Heparin $(50 \mathrm{U} / \mathrm{kg})$ was administered intravenously on completion of vascular access.

The proximal axillary artery was exposed through a small infra- or supraclavicular incision. Two 5-0 Prolene continuous purse sutures were placed on the anterior face of the artery. A 7F sheath was inserted in the middle of the purses using a percutaneous technique, and the native valve was crossed using a conventional technique that includes a straight wire. After hemodynamic transvalvular gradient and telediastolic ventricular pressure measurement, a manually preshaped Stiff wire was placed in the ventricular cavity. The $18 \mathrm{~F}$ sheath was then carefully inserted (Figure E1), and its progression was followed using fluoroscopic guidance. An aortic angiography was performed and displayed during the procedure to facilitate subsequent positioning of the sheath and prosthesis. The tip of the sheath was positioned in the upper part of the ascending aorta (Figure 1, $A, B$ ). Balloon valvuloplasty was performed using 22- and 25-mm balloons (Nucleus, NuMED Inc, Hopkinton, NY) for the 26- and 29-mm Medtronic CoreValve prostheses, respectively. After balloon deflation, rapid pacing was stopped and the balloon catheter was withdrawn. The valve was then advanced and deployed using repeated fluoroscopic controls. The prosthesis was positioned so that it protruded 4.0 to $8.0 \mathrm{~mm}$ out of the calcified native valve leaflets. During prosthesis implantation, no rapid pacing was used. A coordinated approach was used wherein one operator maintained ideal valve positioning by pulling slowly on the catheter during valve release, while the second operator turned the release knob that would deliver the valve. Aortic root angiographies were performed to assess valve position during implantation. After full release of the valve, a coaxial stiff wire position was maintained in the left ventricular cavity and a pigtail was advanced to measure the transvalvular gradient and then removed carefully. Aortic root angiography and echocardiography were performed to reassess valve competency, using standard criteria, and to evaluate the aortic regurgitation severity. After procedure completion, the subclavian arterial access site was surgically closed or repaired, when needed, after purse straining (Figure E2), and a control angiogram was performed. Patients were then transferred to the intensive care unit for 24 to 48 hours of observation. Patients continued taking aspirin indefinitely and clopidogrel for 6 months. Clinical follow-up and transthoracic echocardiograms were performed within 24 hours of the procedure and at 1 and 4 weeks after the device implantation.

\section{RESULTS}

\section{Patient Outcome}

Valve implantation was attempted in 17 consecutive patients between January and September of 2009 in the above-mentioned centers. Complete follow-up was pursued to conclusion in all 17 patients. Preoperative characteristics are shown in Table 1. All patients enrolled had severe symptomatic aortic stenosis with a mean transvalvular gradient of $47 \pm 13.3 \mathrm{~mm} \mathrm{Hg}$. The preprocedural mean aortic valve area was $0.6 \pm 0.3 \mathrm{~cm}^{2}$. The procedure was performed under general anesthesia (13 patients) or local anesthesia in combination with mild sedative-analgesic treatment. The use of transesophageal echocardiographic guidance was not systematic and was left to the discretion of the operators. Percutaneous placement of the $18 \mathrm{~F}$ sheath was successful in all cases. All patients underwent planned open surgical access site closure. No vascular complications requiring surgical repair was observed. In one patient, because of initially low valve implantation, secondary migration occurred while trying to reposition the valve. The valve was positioned in the middle of the ascending aorta, and a second valve was successfully implanted using the same subclavian access.

Prosthesis implantations were uneventful in this small series. The 2 patients who had undergone operation via a supraclavicular incision presented minor and transitory neurologic arm deficit that recovered before patient discharge. One patient had a transient ischemic attack, and 

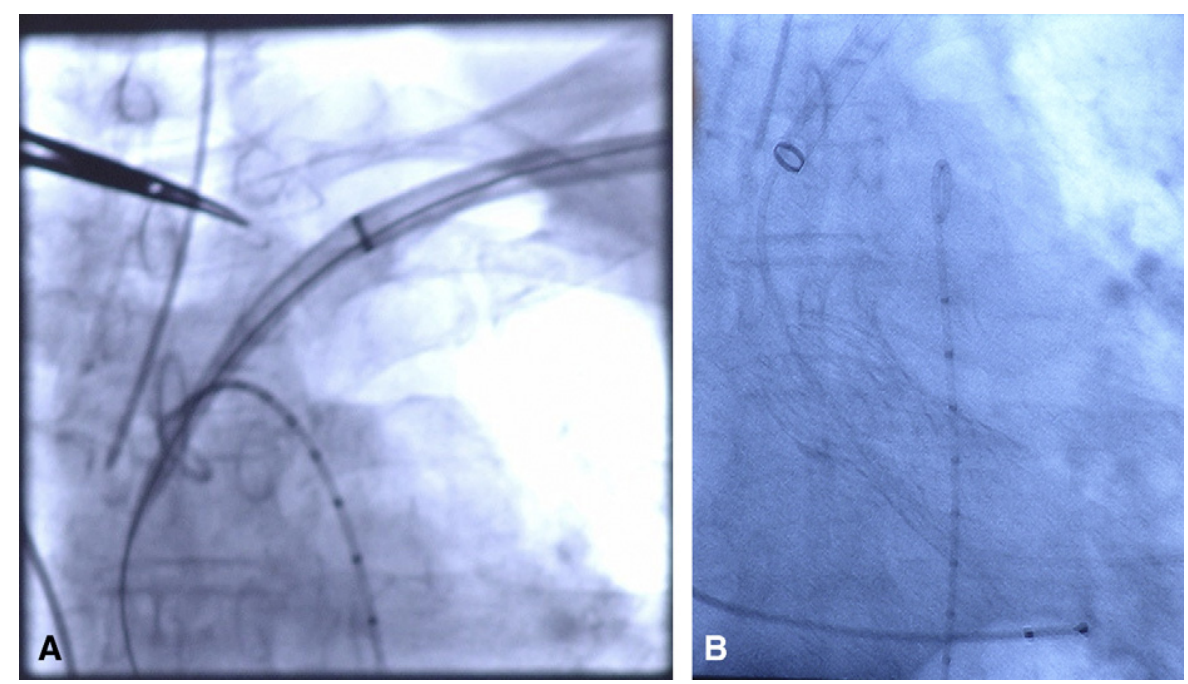

FIGURE 1. Angiogram sheath views in the subclavian and axillary arteries (A) and ascending aorta (B).

1 patient had retrograde aortic dissection during guide wire insertion. The dissection had healed by the end of the procedure once the subclavian artery was repaired. There were no intraprocedural deaths. Intraoperative and postoperative details are shown in Tables 2 and 3.

\section{Valve Function}

Paravalvular leak, as assessed by angiography and echocardiography controls, was trivial (grade 0-1) in most cases $(\mathrm{n}=14)$. There was no severe postprocedural aortic regurgitation (grade $\geq 3$ ).

Valve function, as assessed by echocardiography within 24 hours after implantation, before discharge, and at 1 month, remained essentially unchanged (Table 4). In 2 patients, moderate paravalvular leak occurred immediately after valve implantation, which seemed to be caused by an insufficiently expanded frame. Additional valvuloplasty

TABLE 1. Baseline characteristics

\begin{tabular}{lc}
\hline \multicolumn{1}{c}{ Age, $\mathbf{y}$, mean $\mathbf{\pm}$ SD } & $\mathbf{7 1} \mathbf{\pm 1 1} \mathbf{~ y}$ \\
\hline Angina, n (\%) & 0 \\
Heart failure, n (\%) & 26 \\
NYHA III and IV failure class & 40 \\
Syncope, n (\%) & 13.3 \\
Male gender, n (\%) & 46.2 \\
Diabetes mellitus, n (\%) & 20 \\
Coronary heart disease, n (\%) & 53.3 \\
Porcelain aorta, n (\%) & 0 \\
Prior bypass graft surgery, n (\%) & 26.6 \\
Prior angioplasty, n (\%) & 20 \\
Renal dysfunction,* n (\%) & 6.6 \\
Logistic euroSCORE predicted mortality, mean \pm SD, \% & $34 \pm 11$ \\
Left ventricle ejection fraction \% mean & $52 \pm 14$ \\
\hline NYHA, New York Heart Association; SD, standard deviation. *Estimated glomerular \\
filtration rate > 60.
\end{tabular}

after implantation, with a slightly oversized balloon under rapid pacing, reduced severe paravalvular insufficiency to trivial in both cases without apparent damage to the valve leaflets, the lack of which was assessed by the absence of a central leak during the echocardiographic control. At 30 days and the last day of follow-up, the mean paravalvular leak remained unchanged.

\section{DISCUSSION}

TAVI represents a less-invasive alternative to open surgery indicated in the treatment of aortic stenosis in elderly and high-risk patients. ${ }^{6,19}$ However, major concerns remain, mainly related to the access route and ways to optimize prosthesis implantation. In patients with iliofemoral arteriopathy, transfemoral access may turn out to be unfeasible or too high risk. The development of narrower sheaths may not be the only solution to ensure implantation success. When a transarterial route is not accessible, a transapical approach may be an interesting alternative in some patients. ${ }^{20}$ However, because the approach requires thoracotomy and left ventricular puncture, it may not be suitable in fragile patients, especially in those with severe respiratory or ventricular dysfunction. The

TABLE 2. Procedural outcome

\begin{tabular}{lc}
\hline Successful valvuloplasty & $100 \%$ \\
Successful prosthesis implantation & $100 \%$ \\
Death, intraprocedure & 0 \\
Stroke, minor & 0 \\
Cardiac perforation & 0 \\
Ventricular fibrillation & 0 \\
Emergency cardiac surgery & 0 \\
Transfusion rate $\leq 2$ units & $43 \%$ \\
Hospital stay (d) & 9,4 \\
Myocardial infarction & $0 \%$ \\
\hline
\end{tabular}


TABLE 3. Postprocedural outcome (follow-up of 30 days)

\begin{tabular}{ll}
\hline Death & 2 patients \\
Thromboembolism & $0 \%$ \\
Transient ischemic attack & 1 patient \\
Myocardial infarction & $0 \%$ \\
Aortic dissection & 1 patient \\
Tamponade & $0 \%$ \\
Conversion to surgery & $0 \%$ \\
NYHA class I and II & $100 \%$ \\
endocarditis & $0 \%$ \\
\hline Values are n $\%$ und
\end{tabular}

axillary approach is safe, feasible, and familiar to cardiovascular surgeons. In comparison with the transfemoral approach, positioning the valve and controlling its release proved considerably easier and offered greater movement precision. The short distance between the subclavian artery and the aortic annulus might explain a sense of increased control of the delivery catheter and guide wire. The subclavian and proximal axillary arteries are of good size and usually only moderately diseased even in the oldest population groups. The vessels could be approached through an infraor a supraclavicular incision, especially in patients with pacemakers implanted in the infraclavicular area to avoid infective endocarditis risk. We used this route in 2 patients with a history of pacemaker implantation. As in our routine practice for transfemoral implantation, we did not use transesophageal echocardiography control during valve positioning. We currently indicate a transesophageal echocardiography study in case of tamponade suspicion at the end of the procedure.

Although the left subclavian artery is the preferred access point, used in 15 of our 17 patients, the right subclavian artery ${ }^{21}$ has also been safely used in 2 patients. It is important to note that for a right subclavian approach, the angle between the aortic annulus plan and the horizontal line should no be greater than 20 to 25 degrees to achieve a safe implantation.

This study reports a real-life prospective study of selected high-risk patients with degenerative aortic valve stenosis who were treated with TAVI using subclavian or axillary access. The results of this prospective series of 17 patients, in accordance with similar recently published articles, confirm

TABLE 4. Echocardiographic characteristics

\begin{tabular}{lccc}
\hline & Baseline & Postprocedure & 1 mo \\
\hline $\begin{array}{l}\text { Gradient mm Hg, mean } \\
\text { Valve area, }{ }^{*} \mathrm{~cm}^{2} \text {, mean } \pm \mathrm{SD}\end{array}$ & $0.6 \pm 0.3$ & $1.44 \pm 0.35$ & $1.44 \pm 0.35$ \\
$\begin{array}{l}\text { Annulus diameter, mm, } \\
\quad \text { mean } \pm \mathrm{SD}\end{array}$ & $27.2 \pm 5.5$ & $\mathrm{NC}$ & $\mathrm{NC}$ \\
$\begin{array}{l}\text { Aortic valve insufficiency, } \\
\quad \text { grade } \leq 2\end{array}$ & $0 \%$ & $20 \%$ & $13.3 \%$ \\
$\begin{array}{l}\text { Aortic paravalvular insufficiency, } \\
\quad \text { grade } \leq 2\end{array}$ & $\mathrm{NA}$ & $20 \%$ & $20 \%$ \\
$\begin{array}{l}S D, \text { Standard deviation; } N C \text {, not calculated; } N / A, \text { not applicable. } * \text { Derived from con- } \\
\text { tinuity equation. }\end{array}$ &
\end{tabular}

the feasibility of the procedure. ${ }^{18,19,22}$ Optimal positioning of the prosthetic valve is mandatory to reduce risk of embolization, paravalvular insufficiency, and coronary obstruction. Because of the shorter distance between the arterial entry point and the implantation site, when compared with the femoral access, axillary or subclavian access provides better sheath and delivery catheter stability, increasing the accuracy of positioning the valve and reducing procedure time. Moreover, subclavian vascular repair was easily performed and surgical control of the access point allowed for limited risk of immediate or delayed vascular complications, as observed with the percutaneous transfemoral access.

This approach is also feasible in patients with coronary artery bypass grafting history with a patent left internal thoracic artery or right internal thoracic artery bypass. In our series, 2 patients with patent left and right internal thoracic arteries received implants using the right subclavian access. Nevertheless, this access route should be considered carefully in such situations because of the potential risk of subclavian dissection that may compromise graft patency; ${ }^{19}$ a minimum artery diameter of 6.5 to $7 \mathrm{~mm}$ should be required. The transfusion rate in our series, in a population with preoperative anemia, was high $(43 \%$ of patients, $\leq 2$ units), although no major bleeding complications occurred throughout the study. Unlike in other reports that have referred to major bleeding or access site bleeding rates, ${ }^{23,24}$ which are difficult to evaluate and compare, we preferred to calculate the transfusion rate allowing for a faithful reflection of bleeding complication rates.

Although stroke is a known risk of routine balloon valvuloplasty, ${ }^{25,26}$ none of our patients experienced an ischemic cerebrovascular event. However, 2 patients who underwent operation via supraclavicular access experienced transitory proximal neurologic deficits of the forearm secondary to plexus brachial damage.

Severe (grade $>2$ ) paravalvular leak was not observed in our series. Paravalvular leaks altogether were uncommon and seemed to result from large calcifications positioned between the prosthesis and the annulus causing incomplete sealing. Two patients required iterative balloon valvuloplasty inside the prosthesis, all during the same procedure and using the same valvuloplasty balloon, to reduce paravalvular leaks responsible for aortic regurgitation greater than grade 2. In our study, the length of hospital stay was relatively long. This can easily be explained by the degree and severity of comorbidity of the study population at higher risk than the population of patients who are usually encountered in hospital practice. During follow-up, 2 patients died of noncardiovascular causes. Confirmation of the efficacy and safety of this technique will require a larger population. We believe the relative ease offered by the transaxillary route compares favorably with our experience of the transfemoral access, allowing more accuracy in 
implanting the valve and, as a result, lower average grades of paravalvular leak.

\section{CONCLUSIONS}

Percutaneous aortic valve implantation is an emergent technology with potential benefit in many patients. Current application of this procedure is limited to patients who are poor candidates for surgical valve replacement. Among this aging population, a number of patients do not meet the criteria for percutaneous transfemoral implantation because of the lack of suitable femoral arterial access. The transaxillary or subclavian approach in patients with difficult or unsuitable iliofemoral arteries represents a safe, feasible, and technically interesting alternative.

The authors thank Dr Christopher Hurt for important collaboration.

\section{References}

1. Task Force. Guidelines for the management of patients with valvular heart disease: executive summary. Circulation. 1998;98:1949-84.

2. Roques F, Nashef SA, Michel P, Gauducheau E, de Vincentiis C, Baudet E, et al. Risk factors and outcome in European cardiac surgery: analysis of the EuroSCORE multinational database of 19030 patients. Eur J Cardiothorac Surg. 1999; 15:816-22.

3. Otto CM, Mickel MC, Kennedy JW, Alderman EL, Bashore TM, Block PC, et al. Three-year outcome after balloon aortic valvuloplasty: insights into prognosis of valvular aortic stenosis. Circulation. 1994;89:642-50.

4. Lieberman EB, Bashore TM, Hermiller JB, Wilson JS, Pieper KS, Keeler GP, et al. Balloon aortic valvuloplasty in adults: failure of procedure to improve long-term survival. J Am Coll Cardiol. 1995;26:1522-8.

5. Andersen HR, Knudsen LL, Hasenkam JM. Transluminal implantation of artificial heart valves: description of a new expandable aortic valve and initial results with implantation by catheter technique in closed chest pigs. Eur Heart J. 1992; 13:704-8.

6. Cribier A, Eltchaninoff H, Bash A, Borenstein N, Tron C, Bauer F, et al. Transcatheter implantation of balloon-expandable prosthetic heart valves: early results in an animal model. Circulation. 2001;104(suppl 2). I-552.

7. Webb JG, Munt B, Makkar R, Naqvi T, Dang N. A percutaneous stentmounted valve for treatment of aortic or pulmonary valve disease. Cathet Cardiovasc Interv. 2004;63:89-93.

8. Sochman J, Peregrin JH, Pavcnik D, Timmermans H, Rosch J. Percutaneous transcatheter aortic disc valve prosthesis implantation: a feasibility study. Cardiovasc Intervent Radiol. 2000;23:384-8.

9. Lutter G, Kuklinski D, Berg G, Von Samson P, Martin J, Handke M, et al. Percutaneous aortic valve replacement: an experimental study. $J$ Thorac Cardiovasc Surg. 2002;123:768-76.

10. Boudjemline Y, Bonhoeffer P. Steps toward percutaneous aortic valve replacement. Circulation. 2002;105:775-8.
11. Boudjemline Y, Bonhoeffer P. Percutaneous implantation of a valve in the descending aorta in lambs. Eur Heart J. 2002;23:1045-9.

12. Vassiliades TA Jr, Block PC, Cohn LH, Adams DH, Borer JS, Feldman T, et al. The clinical development of percutaneous heart valve technology: a position statement of the Society of Thoracic Surgeons (STS), the American Association for Thoracic Surgery (AATS), and the Society of Cardiovascular Angiography and Intervention (SCAI). Cathet Cardiovasc Interv. 2005;65:73-9.

13. Cribier A, Eltchaninoff H, Bash A, Borenstein N, Tron C, Bauer F, et al. Percutaneous transcatheter implantation of an aortic valve prosthesis for calcific aortic stenosis. Circulation. 2002;106:3006-8.

14. Cribier A, Eltchaninoff H, Tron C, Bauer F, Agatiello C, Sebagh L, et al. Early experience with percutaneous transcatheter implantation of heart valve prosthesis for the treatment of end-stage inoperable patients with calcific aortic stenosis. J Am Coll Cardiol. 2004;43:698-703.

15. Sakata Y, Syed Z, Salinger MH, Feldman T. Percutaneous balloon aortic valvuloplasty: antegrade transseptal vs. conventional retrograde transarterial approach. Cathet Cardiovasc Interv. 2005;64:314-21.

16. Lichtenstein SV, Cheung A, Ye J, Thompson CR, Carere RG, Pasupati S, et al. Transapical transcatheter aortic valve implantation in humans: initial clinical experience. Circulation. 2006;114:591-6.

17. Asgar AW, Mullen MJ, Delahunty N, Davies SW, Dalby M, Petrou M, et al. Transcatheter aortic valve intervention through the axillary artery for the treatment of severe aortic stenosis. J Thorac Cardiovasc Surg. 2009;137:773-5.

18. De Robertis F, Asgar A, Davies S, Delahunty N, Kelleher A, Trimlett R, et al. The left axillary artery-a new approach for transcatheter aortic valve implantation. Eur $J$ Cardiothorac Surg. 2009;36:807-12.

19. Grube E, Schuler G, Bellesfeld L, Gerckens U, Linke A, Wenaweser P, et al Percutaneous aortic valve replacement for severe aortic stenosis in high risk patients using the second and current third generation self expanding CoreValve prosthesis: device success and 30 day clinical out come. J Am Coll Cardiol. 2007;50:69-76.

20. Zierer A, Wimmer-Greinecker G, Martens S, Moritz A, Doss M. The transapica approach for aortic valve implantation. J Thorac Cardiovasc Surg. 2008;136: 948-53.

21. Ruge H, Lange R, Bleiziffer S, Hutter A, Mazzitelli D, Will A, et al. First successful aortic valve implantation with the CoreValve ReValving System via right subclavian artery access: a case report. Heart Surg Forum. 2008;11:E323-4.

22. Fraccaro C, Napodano M, Tarantini G, Gasparetto V, Gerosa G, Bianco R, et al. Expanding the eligibility for transcatheter aortic valve implantation the transsubcalvian retrograde approach using: the III generation CoreValve revalving system. JACC Cardiovasc Interv. 2009;2:828-33.

23. Marcheix B, Lamarche Y, Berry C, Asgar A, Laborde JC, Basmadjian A, et al. Surgical aspects of endovascular retrograde implantation of the aortic CoreValve bioprosthesis in high-risk older patients with severe symptomatic aortic stenosis. J Thorac Cardiovasc Surg. 2007;134:1150-6.

24. Webb JG, Pasupati S, Humphries K, Thompson C, Altwegg L, Moss R, et al. Percutaneous transarterial aortic valve replacement in selected high-risk patients with aortic stenosis. Circulation. 2007;116:755-63.

25. Holmes DR Jr, Nishimura RA, Reeder GS. In-hospital mortality after balloon aortic valvuloplasty: frequency and associated factors. J Am Coll Cardiol. 1991;17: 189-92.

26. O'Neill WW. Predictors of long-term survival after percutaneous aortic valvuloplasty: report of the Mansfield Scientific Balloon Aortic Valvuloplasty Registry. J Am Coll Cardiol. 1991;17:193-8. 


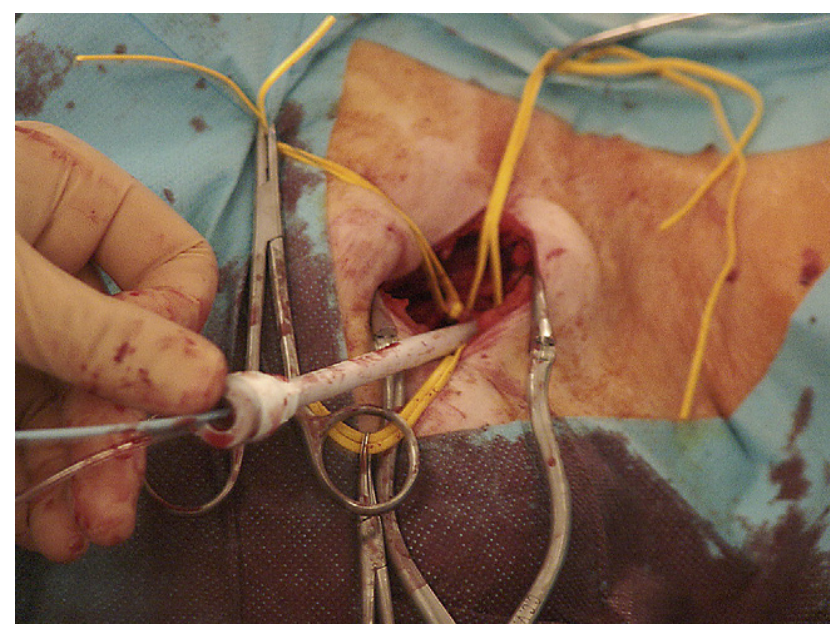

FIGURE E1. Subclavian surgical access; 18F sheath insertion.

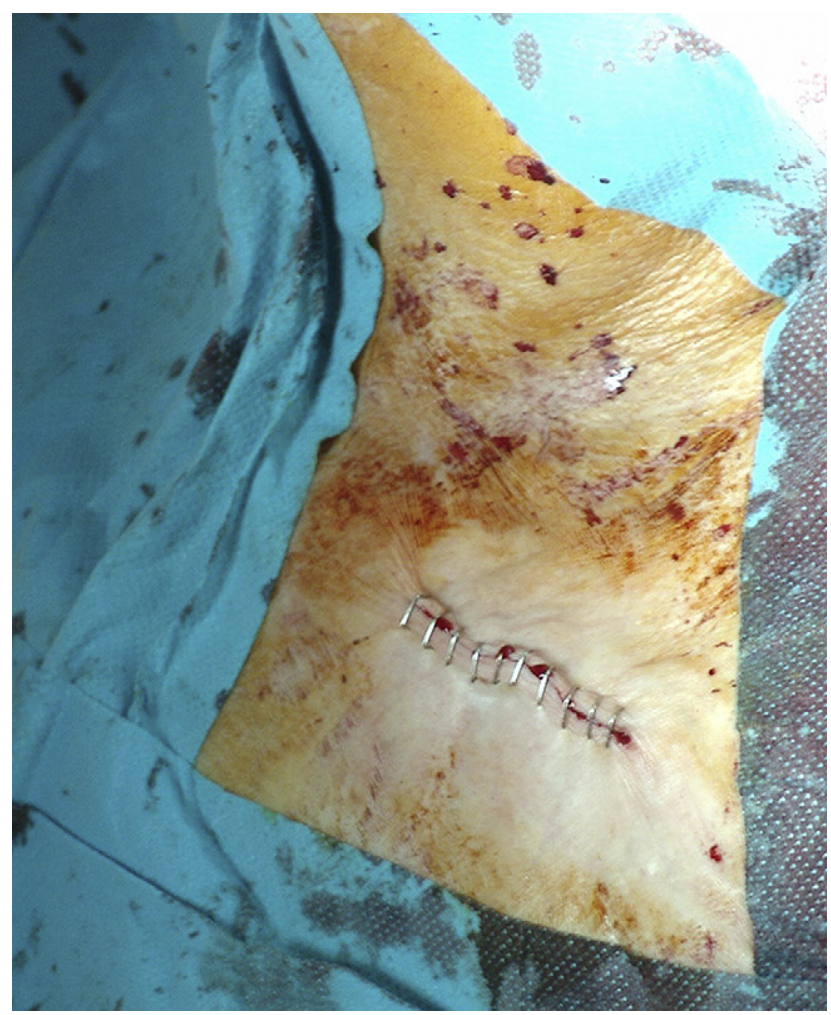

FIGURE E2. Surgical access closed. 